\title{
A Quantitative Review On Acceptance Of Silent Piling Technology Among Designers In Malaysia
}

\author{
Zaiton Ibrahim ${ }^{1, a}$, Nor Azizi Yusoff ${ }^{2, b}$, Suliadi Firdaus Sufahani, ${ }^{3, c}$, \\ Nur Abidah Azhar ${ }^{4, d}$ \\ 1, 2, 4 Department of Infrastructure and Geomatic Engineering \\ ${ }^{3}$ Department Science and Mathematics \\ 1, 2, 4 Faculty of Civil and Environmental Engineering \\ ${ }^{3}$ Faculty of Science, Technology and Human Development \\ University Technology Tun Hussein Onn Malaysia \\ 86400 Parit Raja, Batu Pahat, Johor \\ azaiton@psmza.edu.my, bazizy@uthm.edu.my, 'suliadi@uthm.edu.my, deida.azhar@gmail.com
}

Keywords: Quantitative research, Silent Piling Technology, Acceptance among designers

\begin{abstract}
Normally, the conventional method of piling that uses percussion, vibration or bored piles is less environmental friendly and may contributes to environmental problems. The study was conducted in order to identify the potential of silent piling technology for sustainable implementation. In addition, it is also useful to evaluate the acceptance of this technology and the level of technical knowledge among the engineers who are involved in construction industry, especially in Malaysia. Quanlitative research using questionnaires was considered for this study in order to gain relevant information. The questionnaire was distributed to 43 companies that are registered under ACEM (Association of Consulting Engineers Malaysia). The result shows that there is a great potential for silent piling technology in Malaysia. The technology is accepted among designers at the highest level. Meanwhile, the technical knowledge regarding silent piling technology is also at the highest level. In addition, the result also shows that Press-in technology is highly recommended for the construction industry for sustainable implementation. In conclusion, it is hope that suggestions and strategies can be synergized so that sustainable technology, such as Press-in technology, is applied in Malaysia. The technology is not only useful for the designer, but also the industry, local authorities and universities.
\end{abstract}

\section{Introduction}

The Japanese Ministry of Environment has established seven types of environmental pollution in the construction industry, which are air pollution, water and earth contaminants, bad odour, noise, vibration and ground subsidence [1]. Conventional dynamic piling methods are ill suited to urban development because of their adverse impact of deafening noise complemented by their earth shattering vibrations that has a rippling effect on the environment [2]. Fig.1 shows the public complaints during construction. The 'Press-In' method, with its silent and vibration-free driving process, may be the solution to the widespread problem of noise and vibration on construction sites [2].

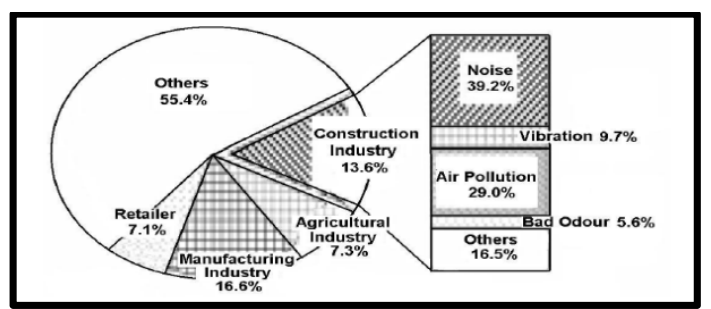

Fig.1Public Complaints during Construction [1] 


\section{Literature Review}

Current Practice of Pile Installation Method in the Construction Industry in Malaysia The conventional method for piling installation such as diesel hammer, drop hammer and vibratory hammer are ill suited in urban areas and has potentially produce the greatest source of noise and ground vibration. Nevertheless, conventional pile driving methods are still widely used in many construction sites though it is cause excessive noise, ground vibration and poses a risk in damaging critical structures [2]. Modern methods such as jacked-in pile, G-pile and silent piling technology are not familiar, because it seems to be costly compared to the conventional method.

Nowdays, the silent piling installation method has been implemented in the construction industry. Fig. 2 shows one of the construction site in which using this technology.

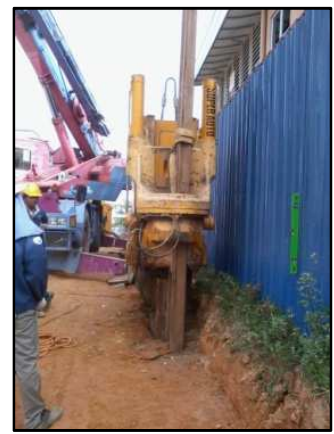

Fig.2 The sheet pile installation at Bukit Serdang, Malaysia (2014)

\section{Quantitative Research}

Quantitative Data Analysis Technique A quantitative data refers to measurable and countable demographic and economic characteristics which cannot be accounted in numerical terms [3]. According to the previous research, this research method is typically considered to be the more "scientific" approach in conducting social science study [4]. In general, the procedure to perform the quantitative research is consists of instrumenting basedquestions, interpreting performance data, assessing attitude data, considering observational data and conducting statistical analysis [5].

\section{Methodology}

Questionnaire Design and Data Collection Reliability analysis is an important analysis to determine whether our data in questionnaire is reliable or not before distribute to the respondents. For this study, pilot study was carried out with 20 respondents who are lecturers at the Sultan Mizan Zainal Abidin Polytechnic and engineers in the government sector such as JKR and JPS. Then, the pilot test analysis is made using the Statistical Package for the Social Science (SPSS) software in order to determine the reliability of the research tools. The Cronbach alpha coefficient obtained was more than 0.7 , suggesting that the items have relatively high internal consistency.

For actual study, a set of questionnaires were distributed by post to 43 civil engineering consultant companies are registered with ACEM (Association Consultancy Engineering Malaysia). These respondents had to return the questionnaires to the researcher within 4 weeks. Theoretically, response rate from respondents vary considerably to as much as $30 \%$, generally. $20 \%$ response can be considered adequate and $80 \%$ response is considered to be high [6]. For this study, the sample size for data analysis was $52 \%$, which are 22 companies registered with ACEM. Therefore, statistically it is acceptable and presentable to answer the research question. 


\section{Data Analysis}

Reliability Analysis for Questionnaire Table 1 shows the Cronbach alpha value from the reliability analysis. From the figure, the value of Cronbach's alpha is more than 0.6 , so the data obtained by analysing the questions to achieve the objectives are verified. High level of reliability means the items or questions contained in the questionnaire can be used to measure the variables that are studied.Reliability means the items or questions contained in the questionnaire can be used to measure the variables to be studied and a good level of reliability is between ' 0.6 to 1.0 ' [7].

Table 1: Cronbach's Alpha Value

\begin{tabular}{lccc}
\hline \multicolumn{1}{c}{ Objective } & Cronbach's Alpha & Total Question & Description \\
\hline $\begin{array}{l}\text { The technical knowledge in silent } \\
\text { piling technology }\end{array}$ & 0.856 & 5 & Acceptable \\
\hline $\begin{array}{l}\text { Potential of silent piling technology } \\
\text { in Malaysia }\end{array}$ & 0.946 & 7 & Acceptable \\
\hline $\begin{array}{l}\text { Acceptance of silent piling } \\
\text { technology }\end{array}$ & 0.771 & 10 & Acceptable \\
\hline $\begin{array}{l}\text { Implementation of sustainability in } \\
\text { the construction industry by using } \\
\text { the Press-in method }\end{array}$ & 0.956 & 8 & Acceptable \\
\hline The demographic of the respondent & 0.308 & 5 & Not Acceptable \\
\hline
\end{tabular}

\section{Result and Discussion}

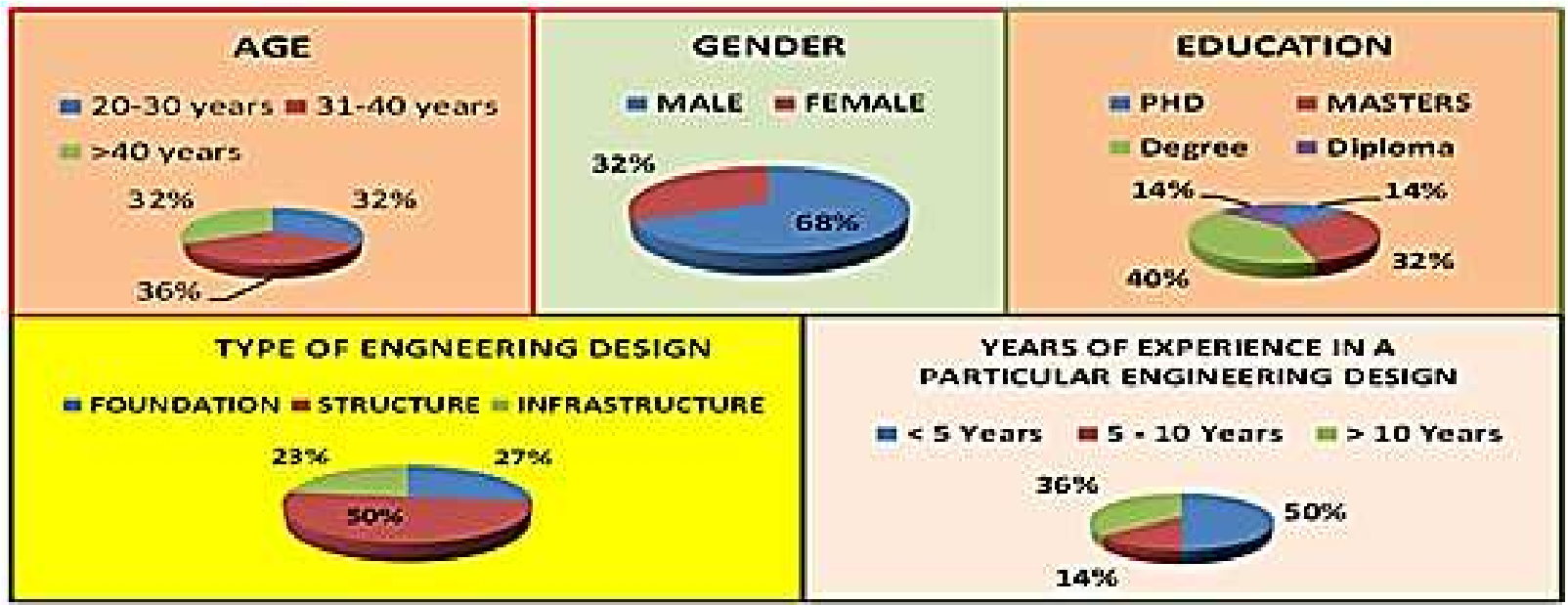

Fig.3 Frequency Analysis for Section A

Frequency Analysis Section A (Demography) Fig.3 shows frequency analysis for demography. Based on the graph, most of the respondent age was between 31 to 40 years old. Then, most of them are male engineers. On the other hand, the educations of respondents that involve in design are mainly bachelor's degree. Apart from that, structural engineers represent the highest percentage for the type of engineering design field based on their position. In conclusion, those who are active in responding to this questionnaire are young engineers that have experience in design of less than 5 years. 


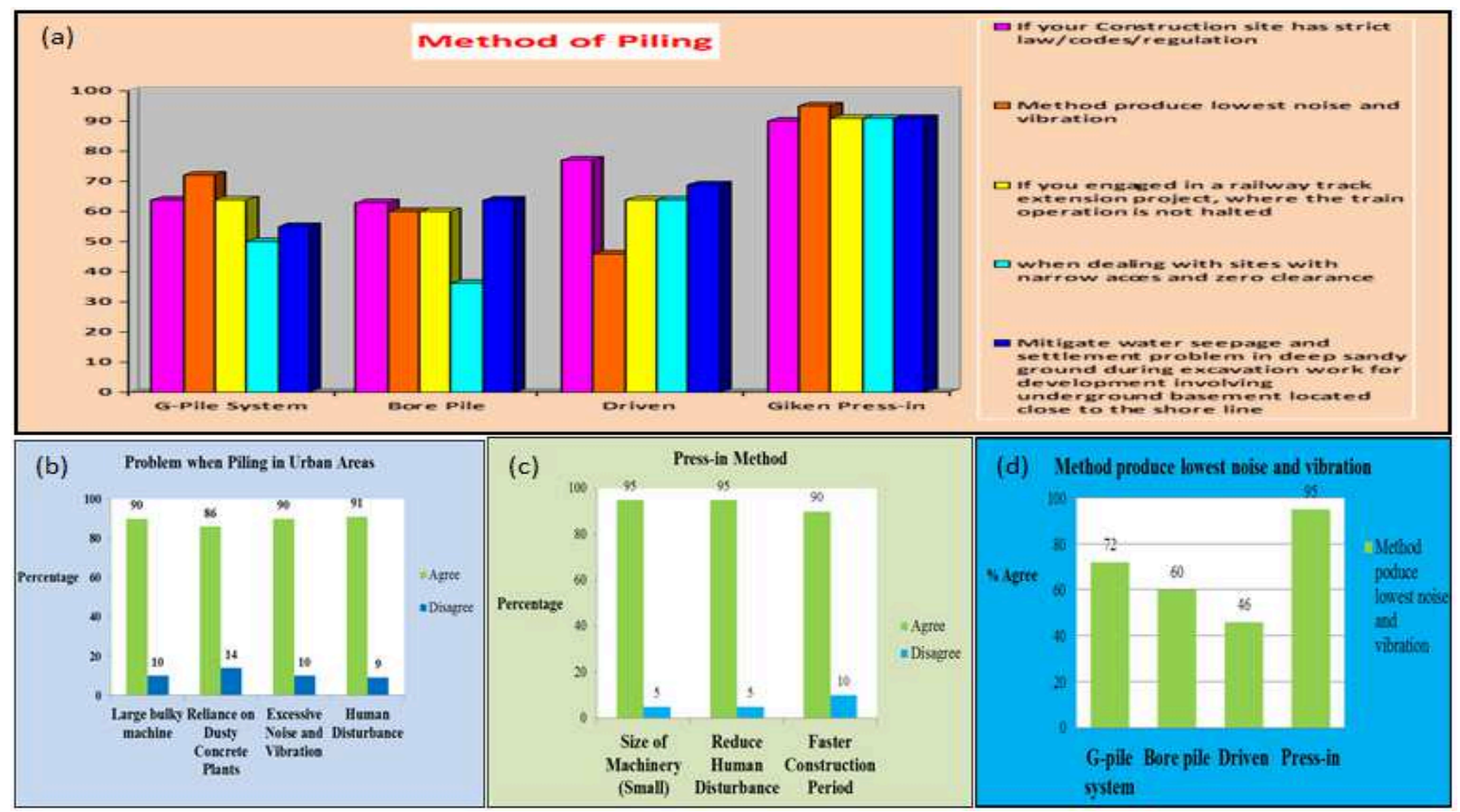

Fig.4 Frequency Analysis for section B

Frequency AnalysisSection B (Survey on Acceptance of Silent Piling Technologies and Sustainability) Based on the Fig.4 (a), the press-in method was the first choice or the method employed with the highest percentage to solve the problems faced by designers at the site. Graph Fig.4 (b) show the problem when piling in urban area and graph Fig.4 (c) show the advantages of press-in method in helping reduce human disturbances, faster completion of construction projects, reduce problem piling at zero clearance access by using small size of machinery. From graph Fig.4 (d), it can be concluded that most of respondents agree that Giken press-in method was the method that produce lowest noise and vibration compared to driven method that produce highest percentage of noise and vibration.

\section{Correlation Analysis}

Table 2: Correlation between two variables

(Dependent variable: Potential of Silent Piling Technology in Malaysia)

\begin{tabular}{lcc}
\hline \multicolumn{1}{c}{ Independent variable } & Pearson Correlation(r) & Description \\
\hline Technical knowledge & 0.590 & Positively strong \\
\hline $\begin{array}{l}\text { Implementation of sustainability in the construction } \\
\text { industry }\end{array}$ & 0.725 & Positively strong \\
\hline Acceptance of silent piling technology & 0.734 & Positively strong \\
\hline Age of designers & -0.156 & Negatively weak \\
\hline Years of Experience in a particular engineering design & -0.344 & Negatively weak \\
\hline Highest designer's education & 0.042 & Positively weak \\
\hline
\end{tabular}


Table 3: P-level between two variables

(Dependent variable: Potential of Silent Piling Technology in Malaysia)

\begin{tabular}{lcc}
\hline \multicolumn{1}{c}{ Independent variable } & p (Significant Level) Description \\
\hline Technical knowledge among designers & 0.0040 & Strong evidence \\
\hline Implementation of sustainability in the construction industry & 0.0001 & Strong evidence \\
\hline Acceptance of silent piling technology among designers & 0.0001 & Strong evidence \\
\hline Age of designers & 0.487 & Weak evidence \\
\hline Years of Experience in a particular engineering design & 0.117 & Weak evidence \\
\hline Highest designer's education & 0.853 & Weak evidence \\
\hline
\end{tabular}

Table 2 and Table 3 shows that the potential of silent piling technology in Malaysia depends on the acceptance of the technology among designers in the industry because in terms of the strength of the relationship from the table, it is found that acceptance shows the highest value of correlation, which is 0.734 compared to technical knowledge and sustainability. On the other hand, age, experience and education show no correlation between potential of silent piling technology because the value of $\mathrm{p}$ more than 0.05 .

\section{Conclusion}

In conclusion, Press-in technology is highly recommended for the construction industry in Malaysia and especially employed by designers working in civil engineering consultant companies. In addition, the potential of this technology and its acceptance by practitioners in the industry is also at the highest level. In a nut shell, most of the respondents agree to consider silent piling technology as sustainable technology in the construction industry. This result may be useful not only for the designer, but also the industry, local authorities and for universities in order to shape and inculcate a more sustainable construction practice in Malaysia. In addition, this research can also introduce new knowledge to designers in Malaysia regarding to the new technologies that are practiced in many other countries such as Singapore, Japan and United Kingdom.

\section{Acknowledgements}

The writer would like to express appreciation to Giken Seisakusho Asia Pte., Ltd., International Press-in Association and UTHM Graduate Incentive Program (GIPS) Sponsorship and many others for giving their support in facilitation the research.

\section{References}

[1] Ministry of the Environment Government of Japan, "Quality of the Environment in Japan 1996”, White Paper, Part II, 1996: http://www.env.go.jp/en/, (1999).

[2] M.Motoyama, T.L.Goh. "Press-in Piling Technology: Development and Current Practice”, Advances in Deep Foundations: London, (2007).

[3] Tolossa, Degefa. "Combining Household Qualitative Data And Quantitative Data In Food Security Research." Innovation creativity, (2005).

[4] T.Richard. "Qualitative versus Quantitative Methods: Understanding Why Qualitative Methods are Superior for Criminology and Criminal Justice." Journal of Theoretical and Philosophical Criminology, (2009).

[5] John W. C. "Research Design Qualitative, Quantitative and Mixed Methods Approaches." SAGE Publications, (2003).

[6] Best J.W., Kahn J.K., "Research in Education", United States of America: Pearson, (2006).

[7] Patton M., "Qualitative Evaluation and Research Method", , Beverly Hills, CA: Sage, (p.169186) (1990). 